\title{
Economic evaluation of land in land fund diversification
}

Mahsudov Muhammadbek Dilshodbek Ugli

Tashkent Institute of Irrigation and Agricultural Mechanization Engineers, Uzbekistan

muhammadbek.maxsudov@bk.ru

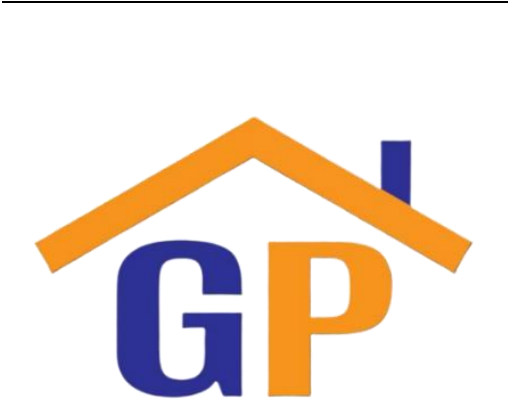

Article History

Received on 13 December 2019

1st Revision on 21 December 2019

2nd Revision on 29 December 2019

3rd Revision on 8 January 2020

Accepted on 16 January 2020

\author{
Abstract \\ Purpose: In this article are discussed modern trends in the economic \\ evaluation of land resources.
}

Research methodology: In carrying out the research work, it is aimed at carrying out the preliminary research work on establishing a system of all land resource utilization in the area. In this, analyzed various economic benefits, measures taken, the experiences of developed countries.

Results: As a result of the study, new methods, clear analytical results were obtained in the practice of economic incentives.

Limitations: The study was carried out solely on the basis of Statistics and internet data.

Contribution: Land use will increase, economic growth will be achieved. The result of the study may be one of the important factors in the achievement of free economic entrepreneurship and free civil society activities.

Keywords: Diversification, Land fund, Evaluation, Economic evaluation, Quantitative assessment, Allocation methods

How to cite: Ugli, M. M. D. (2020). Economic evaluation of land in land fund diversification. International Journal of Financial Accounting and Management, 1(3), 167-172.

\section{Introduction}

The feature of the land as a key tool of agriculture is its productivity. The soil's ability to provide nutrients and moisture to plants is called soil fertility. Natural productivity is created by the nature itself. It will appear and develop under the influence of climate, plants, the relief of the earth, and the rocks in the process of long-term soil formation. It is characterized by physical, chemical and biological properties of soil. But based on natural fertility, the real quality of the land can not be estimated. In the soil, there may indeed be a great deal of nutrients, but for various reasons (moisture, light, etc.), they may be in the form of absorbing or insufficiently absorbing plants.

\section{Literature review and hypotheses development}

In the field of methods of diversification of the land fund, a lot of research has been carried out for the purpose of developing the economy in world practice, mainly in the field of productive use of land, the principles of allocating land for various purposes of use, prospective projects-forecasting on the basis of programs and carrying out various work based on these These Are, I. Ansaff, Evelin Brister, Elizabeth N. Xeyn, Siti Balkis, Bolomchuk B.V, Sharma K.D, Number B, Hansson X, Ferguson R, Olofsson S, Rantamyaki-Laxtinenb L, Brenda B. Lin, Rendel Shalk. The reason is that the research results of the scientists mentioned above were introduced into practice and high economic indicators were achieved.

\section{Research methodology}

Artificial productivity is the result of the combination of human labor on land plots that have natural productivity. In other words, land plots with natural fertility are a subject of work for human activity. Potential or actual productivity is the ability of the soil to meet the demand for nutrients, taking into account natural, climatic and other factors. The main task of a human being is to manage this process, prevent the soil from sinking, and allow the nutrients to absorb the plants. 
The limited land area, the diversity of soils, and the ever-increasing demand for agricultural products require the use of qualitative and unpopular land. This, in turn, is achieved by increasing the amount of capital investment and thus achieving a certain potential productivity. In this regard, the economic productivity of the soil will arise. Economic productivity is understood as a true expression of soil fertility and is characterized by the level of productivity of cultivated agriculture. The economic productivity of the soil is dependent on the amount of capital expenditures, the level of development of production forces and production associations, the processing of products, sales, etc. Economic productivity is subdivided into absolute and relative productivity. Absolute is expressed by the quantity of products grown under certain conditions and is characterized by the productivity indicator of a given area of land.

The market value of the land plots depends on the market demand and supply and the nature of the competition between the buyer and the buyer (claim and supply principle). It can not be more than the probability of acquiring an object of usefulness (replacement principle). The market value of the land parcel depends on the expected amount of revenue, the duration and the probability of earnings (land lease) from the land parcel for a certain period of time, without taking into account the income from other production factors involved in the land parcel for entrepreneurial activity - the principle of waiting. Value of the land parcel can be changed at time and must be determined for a certain date (the principle of volatility). It will change depending on its target, the permitted use area, the rights of other persons on the land parcel, the distribution of the proprietary rights to the parcel, the location and the influence of external factors (the external influence principle). When evaluating it, it should be used for costbenefit, comparative and income-based approaches. Usually, the market value of the land parcel is used to compare, compare, distribute, capitalize land tenure, balance, approximate use. The comparative approach is based on the comparison, deduction, and distribution of sales. The profitability approach is based on the capitalization of land lease, residual, approximate use of land. Elements of cost-benefit approach are used in residual style and extraction method. The requirement to use a sales checking method is the availability of information on transactions with land parcels similar to the land parcel [1].

The method of allocation is used to assess the land plots that are being constructed. When using this method, information on the cost of transactions with real estate objects similar to the object of immovable property, including the land parcel, and the market value of the immovable property may contain information on the potential share of the land parcel. The method of land acquisition capitalization is used to assess land parcels that have been constructed and have not been built. The condition for the use of land lease capitalization is the availability of land rent from the land parcel. The residual land use methodology is the availability of construction and improvement opportunities for earnings. The source of incomes may be the lease of a land parcel or unit of immovable property, economic use or sale of the land parcel or of a real property object at a market value at a particular time. The market value of such land plots is that they need to be able to meet the needs of the user (for a certain period of time) (the principle of profitability). However, since the land market is not yet fully formed and its development is progressing, it is not possible to use all of the above methods in public assessments. Therefore, the cadastral (fiscal) value of land parcels should serve as a target for market value. Spain, Sweden, Germany, every 5-7 years. The area under study (country full) is divided into zones.

The following factors should be analyzed and evaluated in the zoning of the zones: functional use of territories, constructional nature (capital, construction density, layering, etc.), intensification of engineering and transport infrastructure, convenience of the city center and main functional zones, level of development of social infrastructure, historical cost of construction, natural landscapes, availability of recreational resources, ecological condition of the environment, prestige of construction and so on. As the role of market principles in land relations increases, land zoning and cadastral assessment process should introduce new market factors that affect the commercial value of land parcels:

-assessment of multifunctional use of land parcels, assessment of potential requirements for land plots for specific functional areas in different regions in districts and towns, comparison of land plots and real estate markets related to assessment of affected and interlinked value of land plots and affected real estate objects; 
-the increase in the rates of socio-economic rentals of the urban construction costs, the activation of entrepreneurship in the regions, the valuation of land parcels with high commercial interest, the conflict zones and their adjacent urban environment, the absence of obligations on land parcels.

The world experience shows that in developed countries, under the market economy, land prices are faster than other brands or capital. In the US, for example, the price of land increased by $97 \%$ between 1975 and 1980, while consumer goods prices increased by 45\%, respectively, 28 times in Japan between 1955 and 1975 and 3 times in Germany between 1968 and 1980, 6 times and twice. Worldwide, the rate of growth of land prices has always been 2 or 3 times faster than inflation. There is a base for introducing a cadastral assessment system in Uzbekistan. The implementation of it depends on several organizational challenges. The evaluations and interests of professional and public organizations of the appraisers are still limited to the evaluation of some objects and they are unable to carry out the assessment of land in privatization.

Taking into account the above, it is also possible to solve the following major practical issues, based on local conditions:

-firstly, to increase the earnings to the budget and, at the same time, to divert the land tax rate in the city, depending on the cost of urban construction in order to ensure better social justice in the poorer areas;

-secondly, in the absence of an advanced land market, in the urban (district) region, the calculation of land use zones - the use of market prices, as well as the allocation of basic rates for land parcels, including types of land and tenant categories;

-thirdly, the use of land plots in the transfer of property, pledging a land parcel, obtaining bank loans, and applying different coefficients on the valuation zones in collective-share ownership, inheritance or donation [1].

The relative differential is characterized by the productivity of land plots and is characterized by the amount of products that are paid for certain expenses. In order to determine the extent of these fertility, there is a need to undertake land surveys, such as land degradation and land degradation. An economic assessment shows that land is a quality agricultural product, which means that it is important to determine the economic efficiency of using diverse fertile land by taking into account the agricul- tural productivity in the current intensity of farming. The main difference of the cost estimation of land plots is that land acquisition is primarily conditioned by the fact that the soil is not accounted for the natural state, ie the economic conditions of conducting agricultural production. In the economic assessment, the land is considered as the main production tool for agriculture. Based on the goals and requirements, economic evaluation of land may be general and private (individually). Private assessment is conducted to determine the effectiveness of cultivation of specific agricultural crops in a variety of soil conditions. However, private reviews also provide information on the availability of soils for cultivation of various crops and provide certain economic efficiency without additional capital. The general economic assessment is intended to identify indicators of soil productivity and intensiveness of the soil, which will be used to assess the effectiveness of use of land plots at this level [1].

In the economic evaluation of land, it is also important to make the right choice of indicators. They should be objective and have some practical significance. Accordingly, individual valuation of agricultural crops efficiency is carried out according to crop yields, cost recovery and differentiated earnings. An overall assessment of land plots is based on the gross product cost, cost recovery and estimated earnings. Five-year values of natural and economic indices based on economic valuation have been taken: long-term planting of major crops (cotton, rice, corn, beans), pasture crops, yields, gross product, the cost of the unit and labor costs for production, the supply of basic and or revenues of each agricultural crop, the amount and composition of the fertilizers. In the case of permanent irrigation, besides such indicators, the total costs of irrigated lands with reclamation funds, construction costs and construction of irrigation canals are also taken into account [3]. 


\section{Results and discussions}

Land evaluation studies are carried out in the following stages: preparatory works, zoning of land plots, identification of soil germination groups, estimation of bases and cost estimates for land surveying, conducting land surveys, review and approval of assessment materials, assessment of land preparation and distribution of documents. Land survey work at the administrative district level is to define the average value of the evaluation indicators of the whole district, with the generalization of land materials in separate farms. Two cases may be observed: if the whole of the first administrative district is located on the border of a cadastral region, in the second case, the administrative lands may be within two or more cadastral districts. In the first case, the average value of land surveys is determined by one scale for all land areas. In the latter case, the average values will be derived from separate scales for parts of regional coverage that are part of different cadastral districts.

Based on the results of land surveys, the valuation of the main estimate of the main agricultural crops will be based on the valuation of perennial herbage species and the efficiency of cultivation of separate crops, with the average value of the land estimates for the whole district. Economic evaluation of the land is an important part of the land cadastre. The criteria for economic evaluation include:

1. Quantitative evaluation of land. This is the point in determining how many times more or less the place is, more or less, elsewhere, its area or productivity. This criterion can be used in the economic calculations, organizational and management practices in agriculture. It is expressed in points or absolute quantities.

2. The criterion for limiting the impact of objective and subjective factors of agricultural development. The essence of the criterion is that workers employed in industrial enterprises, depending on their discretion, perform work related to a particular category and earn a worthwhile salary. In agriculture, the productivity of workers or farmers, who work at different levels, is low due to the fact that they have a variety of means of production, due to their new and old technology.

3. The criterion for the natural, artificial and productive productivity of the land. It depends on the natural, physical, chemical properties of the soil and its climatic conditions. Artificial productivity is created by human beings. Effective productivity is based on natural and artificial productivity. The fact is that natural labor is closely linked to artificial productivity when it comes to spending a lot of work and money on the ground. Therefore, economic evaluation of land should be assessed for efficiency. Natural productivity is not practiced at this time. There are human activities in all areas of agriculture.

\section{Directions of economic evaluation}

An economic assessment of the land can be done for various purposes. Their main areas are:

1. Overall assessment of land as a means of agricultural production.

2. Economic evaluation of crop yields.

3. Evaluating the impact of increased land quality on additional costs.

The general economic evaluation is a system for each country's territory, requiring a single peak for all government agencies.

The economic assessments mentioned in paragraphs 2 and 3 above refer to specific land plots, which include, but are not limited to, land degradation for a particular purpose, primarily for the type of land cadastre and economic cost overhead costs.

Economic evaluation, in a broad sense, depends on many factors, such as the productivity of the land, the proximity of cities, large populated areas, industrial enterprises, communication routes, small size, shape, cost parts of the land, proximity to one another [2].

The primary cost estimation is carried out according to the soil quality of the soil, analyzed by soil types. It is also important to take into account other factors that determine soil quality, such as water availability, wind erosion, erosion and other impacts.It should be borne in mind that the economic evaluation of the land has the same genetic classification. When considering soil types, it should take into account the characteristics of soil composition, mechanical composition, moisture content, swamping, erosion tendency, culturalization level and other characteristics of soil fertility. If crops, 
meadows and pastures in agriculture are economically evaluated, then the assessment is carried out as described above, but the type and quality of the plant cover is included in the analysis. In the economic assessment of pastures, pastures, their focus is on classification, ecological characteristics and the characteristics of natural forage crops. The main criterion for their evaluation is the proximity of areas [4].

Pastures and pastures can be found on flat areas, low plains, on the slopes of the river, on the slopes, in the mountains and in the high mountains. In the economic evaluation of species, their varieties are taken into account. In general, economic evaluation will take into account a number of criteria. The most important of them are the genetic type of soil, the low content of nutrients, mechanical composition and so on.

Criteria for the complex economic evaluation of population regions in world practice:

- engineering - construction quality, which reflects the suitability of the regions;

- equipped with engineering facilities and trunk communication;

- natural conditions, including recreational value of the territories;

- ecological condition of the environment;

- the location of existing traffic zones relative to the city center, work places and others;

- other aspects of the attractiveness of the area, including the prestige, socio-economic conditions of the population's lives, the administrative status of the city and others.

The starting value of land plots is determined by the local authorities on the basis of the results of complex economic evaluation of lands. The value of the land parcel to determine the initial value is multiplied by the price index (quarterly) determined by the State Committee for Architecture and Construction together with the State Committee on Land Resources, Geodesy, Cartography and State Cadastre. When setting the initial value, it was possible to apply coefficients based on existing demand and supply.

Comprehensive economic evaluation of lands should be determined by the authorities as they have been investing in the improvement of the locality, considering the future development of the engineering infrastructure in the near future.

\section{Conclusion}

The task of developing land relations in the country creates the need for more accurate and systematic accounting of land resources. In the more detailed assessment of the cost of the territory, taking into consideration the other factors and conditions affecting the market price of land parcels, such as servitudes (loaded obligations - private and foreign), immediate neighbors to the land parcel, direct presence in the house, presence of children's playgrounds and recreational green areas. necessary.

Suggested Method:

- the availability of land-based cadastre assessment data and the need to spend most of the time on the use of data from the Complex Economic Evaluation Data;

- encourage the acquisition of land parcels for enterprises and citizens with the possibility of establishing such amount of acquisition based on the principle of payment principle in privatization;

-as a result, this methodology will result in the simplification of the cost of purchasing.

\section{Limitation and study forward}

Economic incentive is an important economic measure in the regulation of the use of land resources and in the implementation of the use of unused land areas. Such measures and measures are carried out on the basis of hukukamt decisions. The successful implementation of this process depends on individuals who have a message from the field of land resources. 


\section{Acknowledgement}

I would like to express my gratitude to the Tashkent Institute of irrigation and agricultural mechanization engineers for their comprehensive assistance in carrying out the research work.

\section{References}

Altiev A.S. (2019). The economic mechanism of liberalizing the land use system: monograph. Tashkent: Fan, 220-224.

Altiev A.S., Mahsudov M.D. (2019). Methods of forecasting and management of land fund diversification in local areas. International Journal of Recent Technology and Engineering, 8 (3), 403-411. DOI: 10.35940/ijrte.C1086.1083S19.

Mahsudov M.D. (2019). Диверсификация землепользования является фактором развития. Monograph. LAP Lambert Academic Publishing, 71-72.

Babajanov A.R., Mahsudov M.D. (2019) Diversification of land fund in the district. Monograph. LAP Lambert Academic Publishing, 77-78.

Altiev A.S. (2019). Regulation of land relations - an important condition of development strategy. Asian Journal Multidimensional Research, 8 (5), 344-350. DOI:10.5958/22784853.2019.00211.8. 